Article

\title{
Effects of the Notch Angle, Notch Length and Injection Rate on Hydraulic Fracturing under True Triaxial Stress: An Experimental Study
}

\author{
Yulong Chen ${ }^{1, *}$, Qingxiang Meng ${ }^{2, *}$ and Jianwei Zhang ${ }^{3, *}$ \\ 1 State Key Laboratory of Hydroscience and Engineering, Tsinghua University, Beijing 100084, China \\ 2 Research Institute of Geotechnical Engineering, Hohai University, Nanjing 210098, China \\ 3 School of Port and Transportation Engineering, Zhejiang Ocean University, Zhoushan 316022, China \\ * Correspondence: chen_yl@tsinghua.edu.cn (Y.C.); tianyameng@hhu.edu.cn (Q.M.); \\ zhangjianwei@zjou.edu.cn (J.Z.)
}

Received: 13 May 2018; Accepted: 15 June 2018; Published: 17 June 2018

\begin{abstract}
This study focused on the effects of the notch angle, notch length, and injection rate on hydraulic fracturing. True triaxial hydraulic fracturing experiments were conducted with $300 \times 300 \times 300 \mathrm{~mm}$ cement mortar blocks. The test results showed that the fracture initiation pressure decreased as the notch length and injection rate increased, whereas, the fracture initiation pressure decreased as the notch angle decreased. Furthermore, the direction of the hydraulic fracture was always along the direction of the maximum principle stress.
\end{abstract}

Keywords: hydraulic fracture; notch angle; notch length; injection rate; triaxial stress

\section{Introduction}

Hydraulic fracturing is a technique for enhancing the hydraulic conductivity of geological formations, and it is currently indispensable for oil and gas extraction [1-7]. It involves pumping a conditioned fluid into a rock formation through a borehole at high pressure to open or connect newly created or pre-existing fractures to form flow pathways. Considerable effort has been devoted toward developing this technique in terms of understanding phenomena and predicting the geometry and characteristics of fractures.

Many experimental investigations of hydraulic fractures have been conducted. Fallahzadeh et al. conducted experiments using 100 and $150 \mathrm{~mm}$ mortar samples (cubes) and found that the fracture initiation and breakdown pressure was dependent on the orientation of the perforations in perforated wellbore [8]. Wanniarachchi et al. investigated the influence of confining pressure on the hydraulic fracturing process and the influence of both confining pressure and injection pressure on the fracture permeability in hydraulically fractured rocks using intact siltstone samples in fracturing and permeability experiments [9]. Chen et al. investigated the hydraulic behavior of natural fractures/joints, in particular, the relationships between fracture offset, mechanical aperture, and hydraulic aperture under different stress conditions through laboratory experiments [10]. Zhou et al. studied the hydraulic fracture propagation behavior and fracture geometry in naturally fractured reservoirs and then investigated the effect of random natural fractures on hydraulic fracture through a series of servo-controlled, tri-axial fracturing experiments [11,12].

In principle, fractures can initiate anywhere along the open borehole section, depending mainly on the variation in permeability and existing flaws. However, if a man-made radial notch could be cut such that it dominates local natural variations, the number of hydraulic fractures could be controlled to grow up from the peripheries of the artificial notches and an expected fracture geometry may be 
achieved [13-17]. In this regard, the quality of a hydraulic fracturing operation is strongly impacted by the notch geometry, including the angle and length, and the injecting fluid properties, such as the injection fluid type and flow rate. The key challenge in hydraulic fracturing is the selection of the most suitable working parameters, including the angle and length of the initial notch and the injection flow rate, to obtain greater production. To maximize the production rate while minimizing the production cost, it is necessary to have comprehensive knowledge of each phase of the hydraulic fracturing process, including the fracture initiation pressure, the geometry of the fracture network generated, and the direction of the major fracture.

In this paper, the effects of the notch angle, notch length, and injection rate on the hydraulic fracture propagation were examined. A series of fracturing experiments was conducted using $300 \times 300 \times 300 \mathrm{~mm}$ cement mortar blocks. Based on the test results, changes in the fracture initiation pressure and the geometry that are attributed to the notch angle and length and the injection rate are discussed. As a result of these experiments, theoretical references are provided for directional hydraulic fracturing.

\section{Experimental Program}

A true triaxial hydraulic fracturing test system was used in this study. As shown in Figure 1, this system consists of a steel framework, a loading system, and a servo injecting pump, which is capable of applying three independent orthogonal stresses up to $28 \mathrm{MPa}$ in three directions on a sample. These stresses were applied to a sample through three pairs of flat jacks which could be controlled separately by a multi-channel, hydraulic voltage stabilizer.

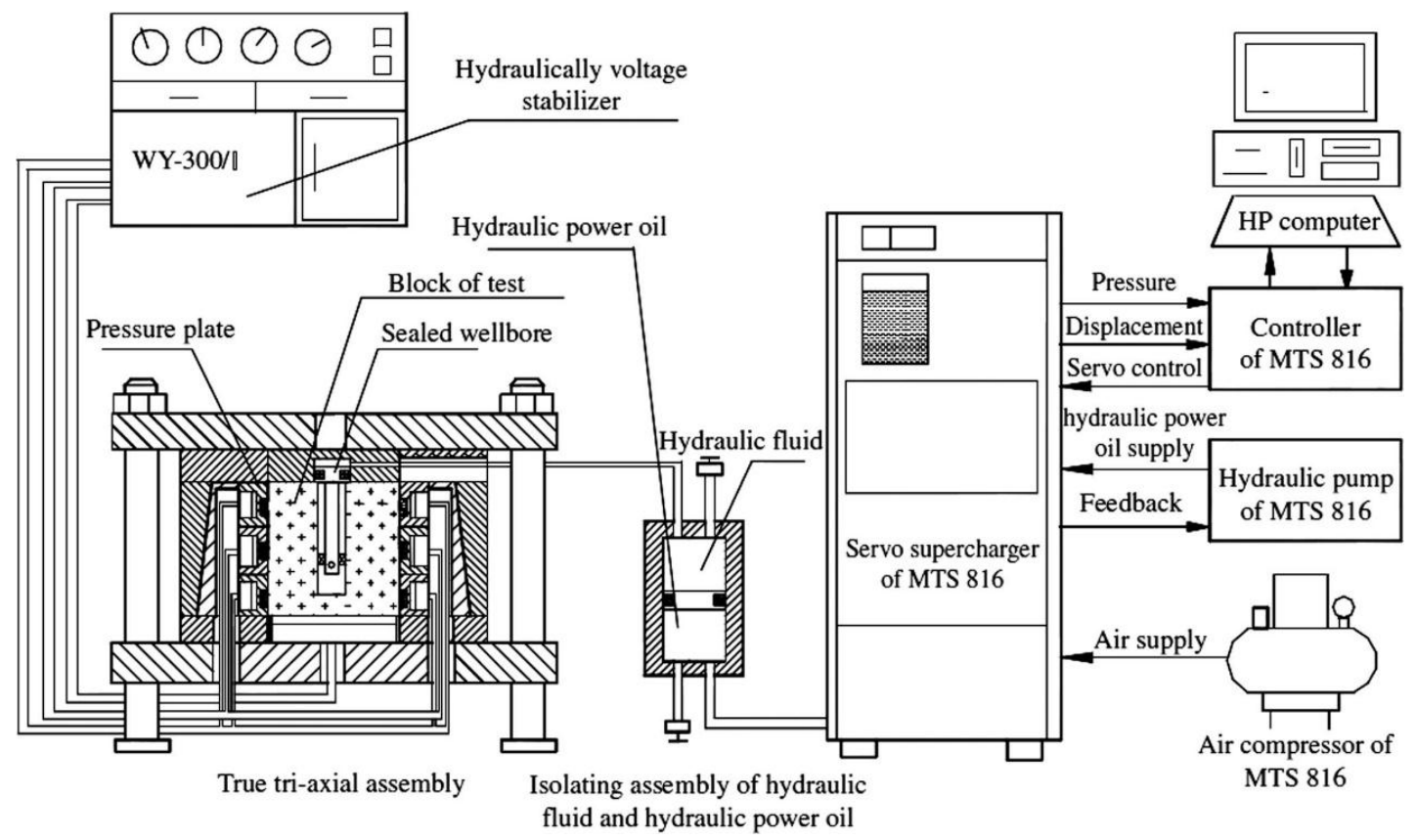

Figure 1. Schematic of the true triaxial hydraulic fracturing test system.

Figure 2 shows the size and structure of the test blocks and the metal casings modeling the notches. Six specimens with different notch angles, notch lengths, and injection rates were prepared in total, and the experiment parameters of the specimens are listed in Table 1 , where $l, \theta, v$, and $p_{i}$ denote the notch length, angle, injection rate, and initiation pressure, respectively. Test blocks with dimensions of $300 \times 300 \times 300 \mathrm{~mm}$ with a single borehole (diameter: $30 \mathrm{~mm}$, length: $150 \mathrm{~mm}$ ) were prepared using cement mortar. A metal casing was placed in the center of the mold. The initial notch was simulated by two circular steel plates with $3 \mathrm{~mm}$ spacing. The model blocks were prepared from a mixture of 
Chinese cement (No. 325) and fine sand. The mechanical parameters of the cement mortar had an unconfined compressive strength of $28.34 \mathrm{MPa}$, a Young's modulus of $8.40 \mathrm{GPa}$ and a Poisson's ratio of 0.23 .

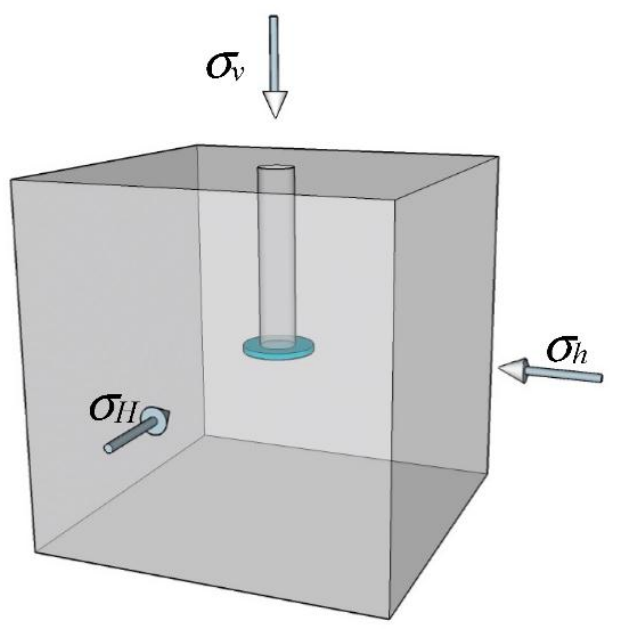

(a)

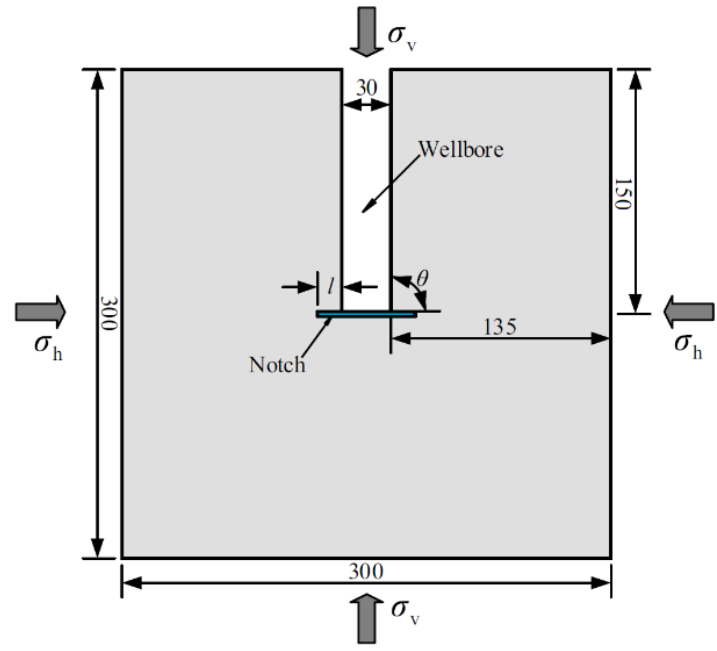

(b)

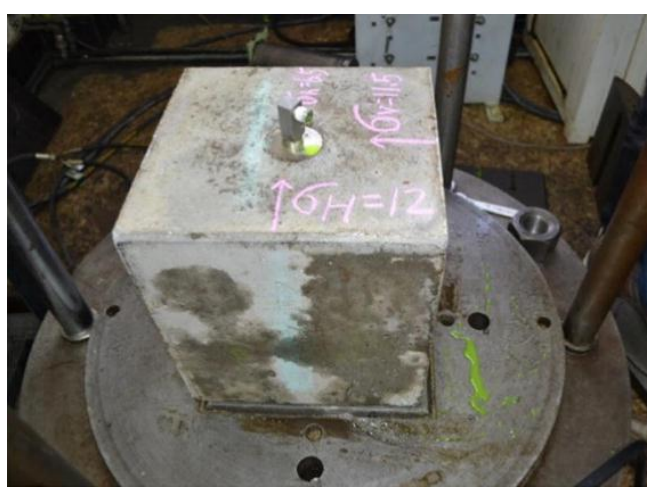

(c)

Figure 2. Diagram of the specimens (units: mm): (a) 3D illustration, (b) size, and (c) photo.

Table 1. Test parameters and initiation pressure of specimens.

\begin{tabular}{cccccc}
\hline Specimen & Stress State & $\boldsymbol{\theta}\left(^{\circ}\right)$ & $\boldsymbol{l}(\mathbf{m m})$ & $\boldsymbol{v}(\mathbf{m m} / \mathbf{s})$ & $\left.p_{\boldsymbol{i}} \mathbf{( M P a}\right)$ \\
\hline 1 & & 90 & 15 & 0.2 & 22.81 \\
2 & $\sigma_{v}=6.5 \mathrm{MPa}$, & 90 & 30 & 0.2 & 20.50 \\
3 & $\sigma_{H}=12.0 \mathrm{MPa}$, & 90 & 30 & 0.4 & 18.29 \\
4 & $\sigma_{h}=11.5 \mathrm{MPa}$ & 45 & 15 & 0.2 & 16.90 \\
5 & & 45 & 15 & 0.4 & 16.15 \\
6 & & 45 & 30 & 0.4 & 16.02 \\
\hline
\end{tabular}

Six block experiments were performed to investigate the different notch angles, notch lengths, and injection rates influencing hydraulic fracture propagation. In the experiments, all of the wellbores were vertical. The notch planes were horizontal for specimens 1-3 and inclined for specimens 4-6. The test block was placed in the true triaxial stress loading framework. The simulated stress field conditions were $\sigma_{v}=6.5 \mathrm{MPa}, \sigma_{H}=12.0 \mathrm{MPa}$, and $\sigma_{h}=11.5 \mathrm{MPa}$, and the stress direction is shown in Figure 2. After the stress had been maintained for $30 \mathrm{~min}$, the fracturing fluid was injected into the wellbore at a constant injection rate. Green guar gum was added to the water tank of the fracture propagation track to improve the detection of hydraulic fracture. The water injection was stopped 
when the water ran out. After the experiments had been performed, the blocks were cut to reveal the discontinuity and hydraulic fracture geometry by analyzing photos taken of each block slice.

\section{Experimental Results and Analysis}

Figure 3 shows the water pressure for the six specimens during hydraulic fracturing. The total experimental process was divided into three stages. At first, when water was injected into the test block, the water pressure increased. Then, the pressure fluctuated, indicating hydraulic fracture initiation and propagation. The fluctuation in pressure indicates the propagation process of the hydraulic fractures. A highly oscillatory curve was observed at sample 4 . This oscillation might have resulted from the formation of a large fracture surface area and local heterogeneity. Finally, the hydraulic fractures connected with the boundary surface and the water pressure decreased.

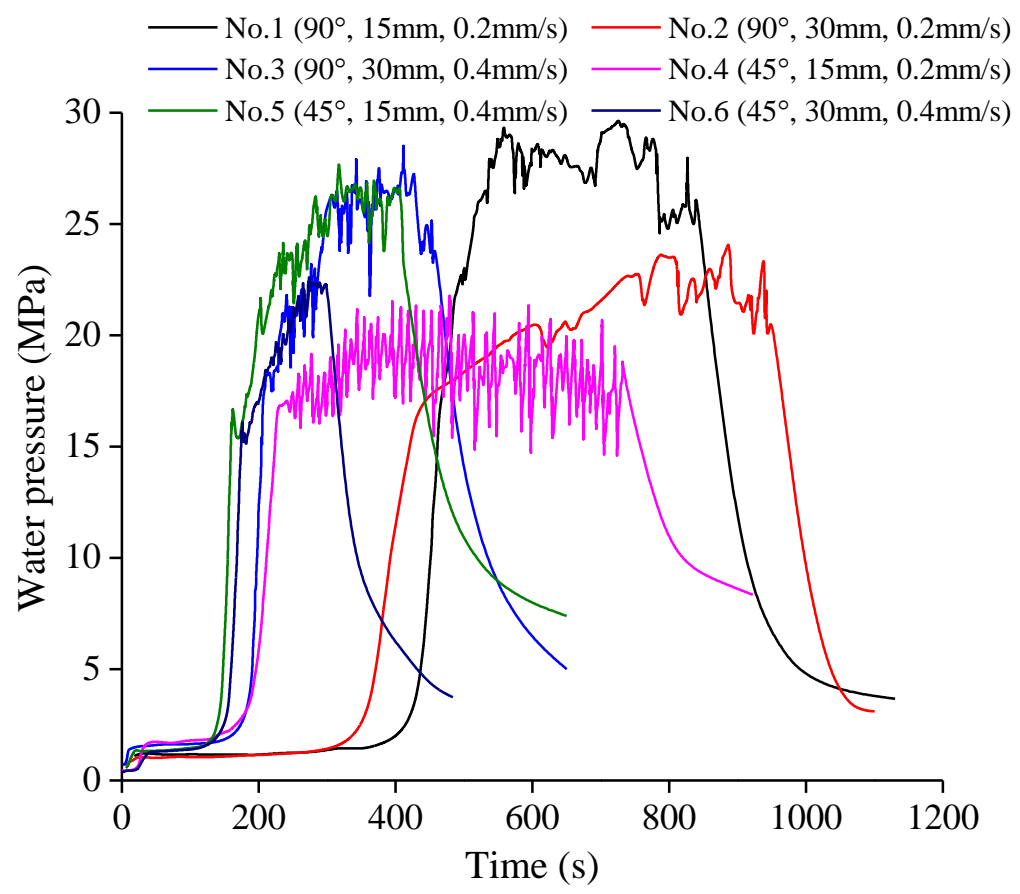

Figure 3. Hydraulic pressure in the hydraulic fracturing process.

The laboratory-obtained drying water pressure curves were different each other due to the effects of the notch length, angle, and the injection rate. The initiation pressures were obtained from these six specimens. The initiation pressure refers to the pressure at the first fluctuation in the water pressure curves.

\subsection{Effect of Notch Angle}

The angle of notch had a significant effect on the hydraulic fracture, as shown in Figures 4 and 5. When $\theta=45^{\circ}$, the water pressure increased faster, and the initiation pressure occurred earlier than when $\theta=90^{\circ}$. Moreover, the initiation pressure for $\theta=45^{\circ}$ was lower than that for $\theta=90^{\circ}$. A lower notch angle accelerated hydraulic fracturing and facilitated the perforation and cutting of the test blocks, whereas, the larger notch angle delayed the initiation and propagation of the hydraulic fractures. 


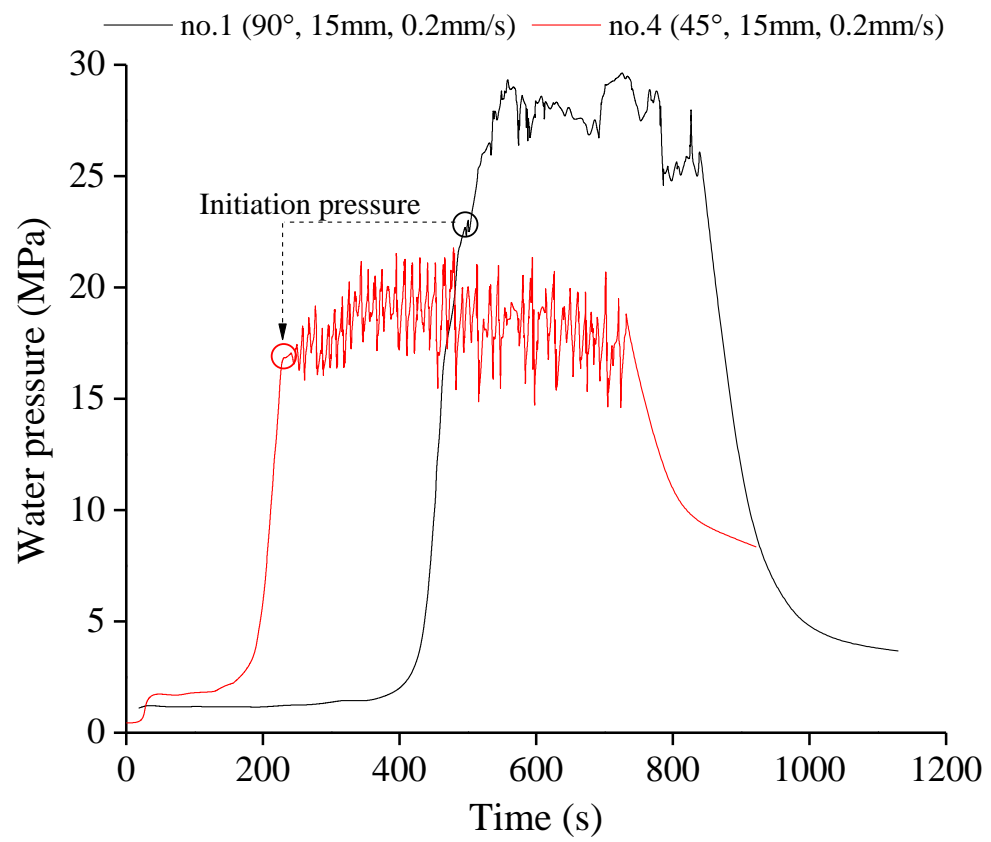

Figure 4. Effect of the notch angle on water pressure when $l=15 \mathrm{~mm}$ and $v=0.2 \mathrm{~mm} / \mathrm{s}$.

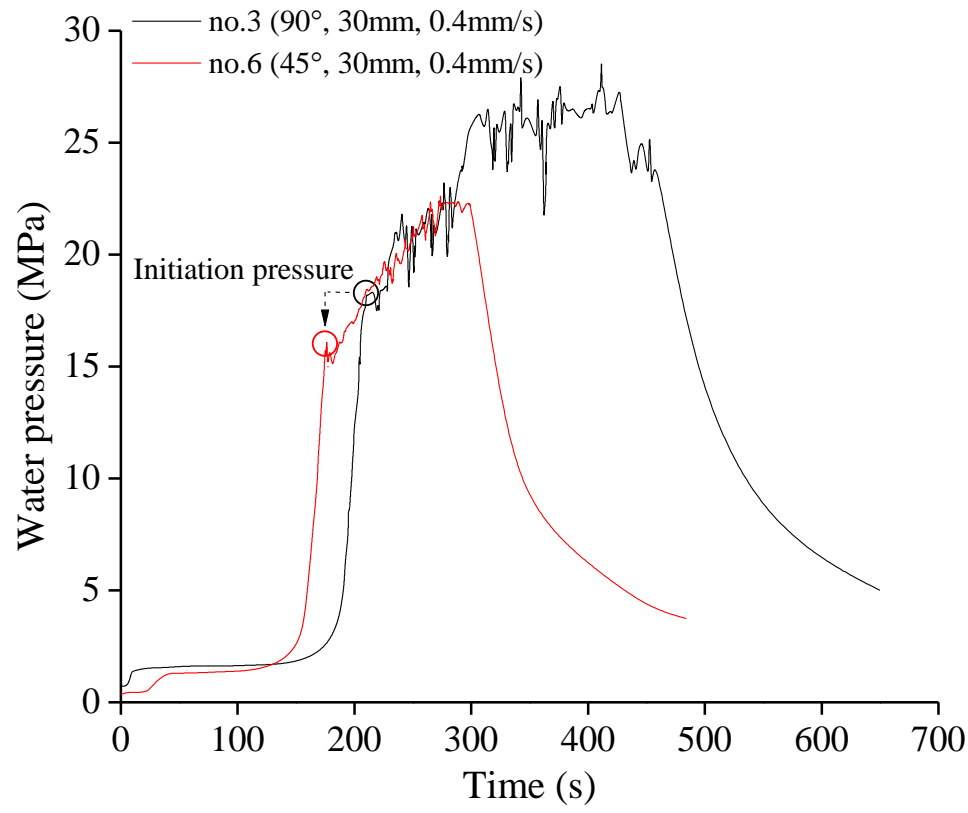

Figure 5. Effect of the notch angle on water pressure when $l=30 \mathrm{~mm}$ and $v=0.4 \mathrm{~mm} / \mathrm{s}$.

\subsection{Effect of Notch Length}

The effect of the notch length on the hydraulic fracture is shown in Figures 6 and 7. A longer notch length generated a smaller initiation pressure. This is because a longer notch produces larger stress concentrations near the notch-tip. This phenomenon may result in fractures initiating preferentially at the ends of the notch. 


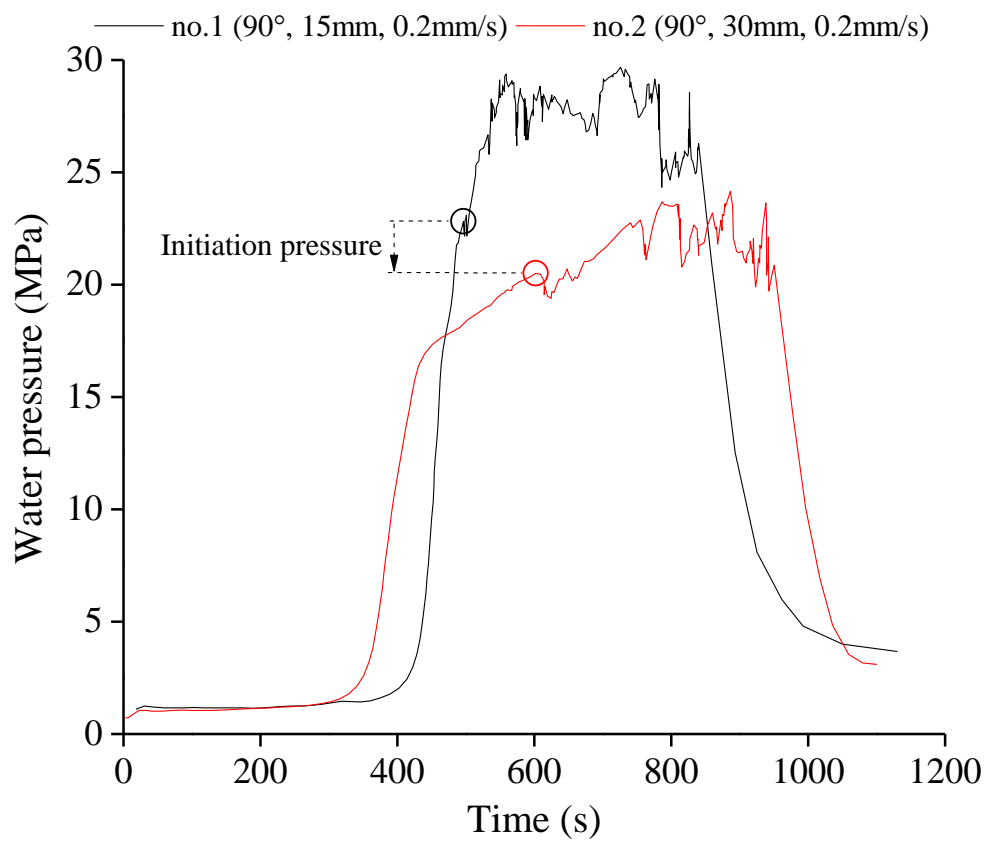

Figure 6. Effect of the notch length on the water pressure when $\theta=90^{\circ}$ and $v=0.2 \mathrm{~mm} / \mathrm{s}$.

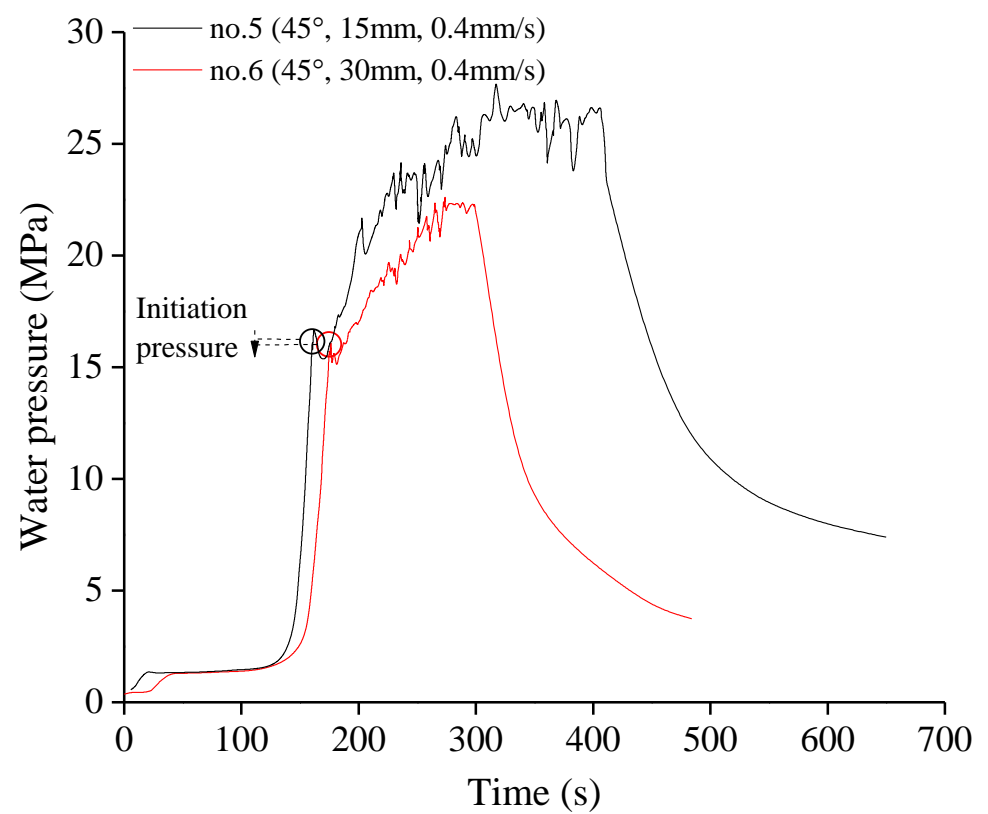

Figure 7. Effect of the notch length on the water pressure when $\theta=45^{\circ}$ and $v=0.4 \mathrm{~mm} / \mathrm{s}$.

\subsection{Effect of Injection Rate}

Figures 8 and 9 indicate the effect of the injection rate on the hydraulic fracture. When the injection rate increased, the initiation pressure reduced, as did the time taken to achieve the initiation pressure. This was mainly because more energy is supplied to the notch as water is injected at a higher flow rate. Consequently, the notch pressurization rate increases. This makes the fracturing process more dynamic, and as a result, a smaller fracture initiation pressure is required to create a fracture. 


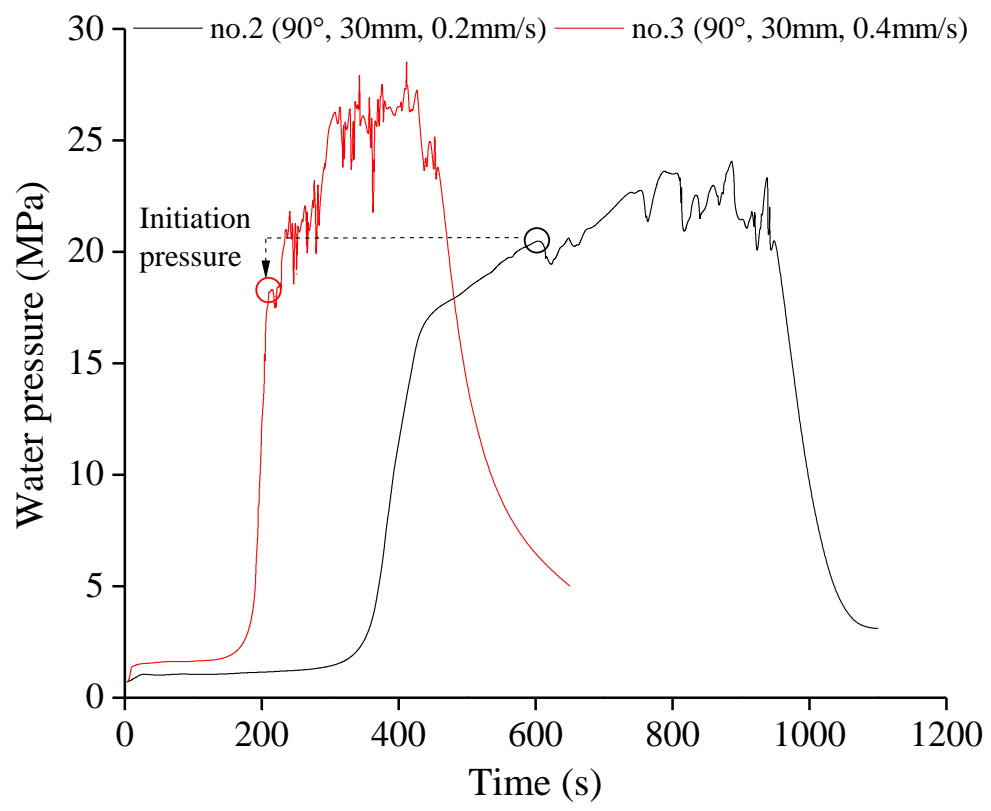

Figure 8. Effect of the injection rate on the water pressure when $\theta=90^{\circ}$ and $l=30 \mathrm{~mm}$.

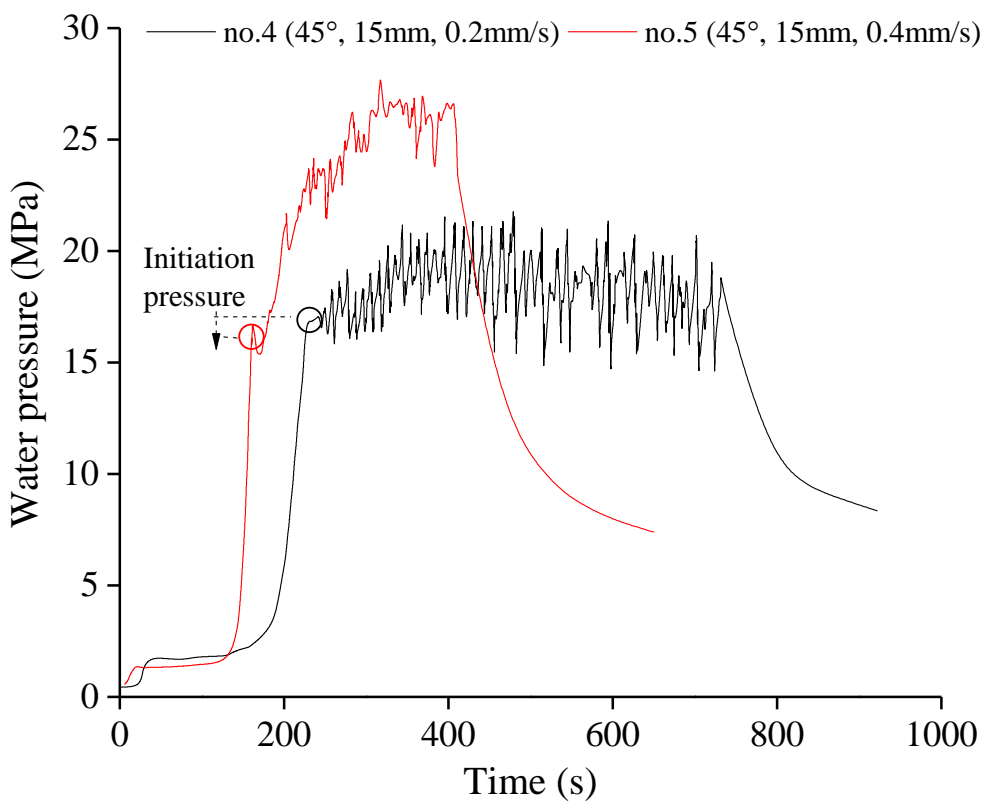

Figure 9. Effect of the injection rate on the water pressure when $\theta=45^{\circ}$ and $l=15 \mathrm{~mm} / \mathrm{s}$.

\subsection{Fracture Geometry}

The geometry of the hydraulic fracture along the notch plane direction plays an important role during the fracturing operation. A more planar fracture plane results in a wider and smoother fracture with less frictional pressure loss. The fracture configurations for six specimens are shown in Figure 10. For specimens with $\theta=90^{\circ}$ (specimens 1, 2, and 3), horizontal fractures were induced. Hydraulic fractures propagated directly along the notch plane regardless of the notch length and injection rate. When $\theta=45^{\circ}$ (specimens 4,5 , and 6), the fractures deviated along the notch plane toward the direction of minimum horizontal stress. The spatial configuration of the hydraulic fracture was a curving surface instead of a plane. It is noteworthy that the propagation mode and configuration of the hydraulic fractures were basically independent of the notch length and injection rate. 


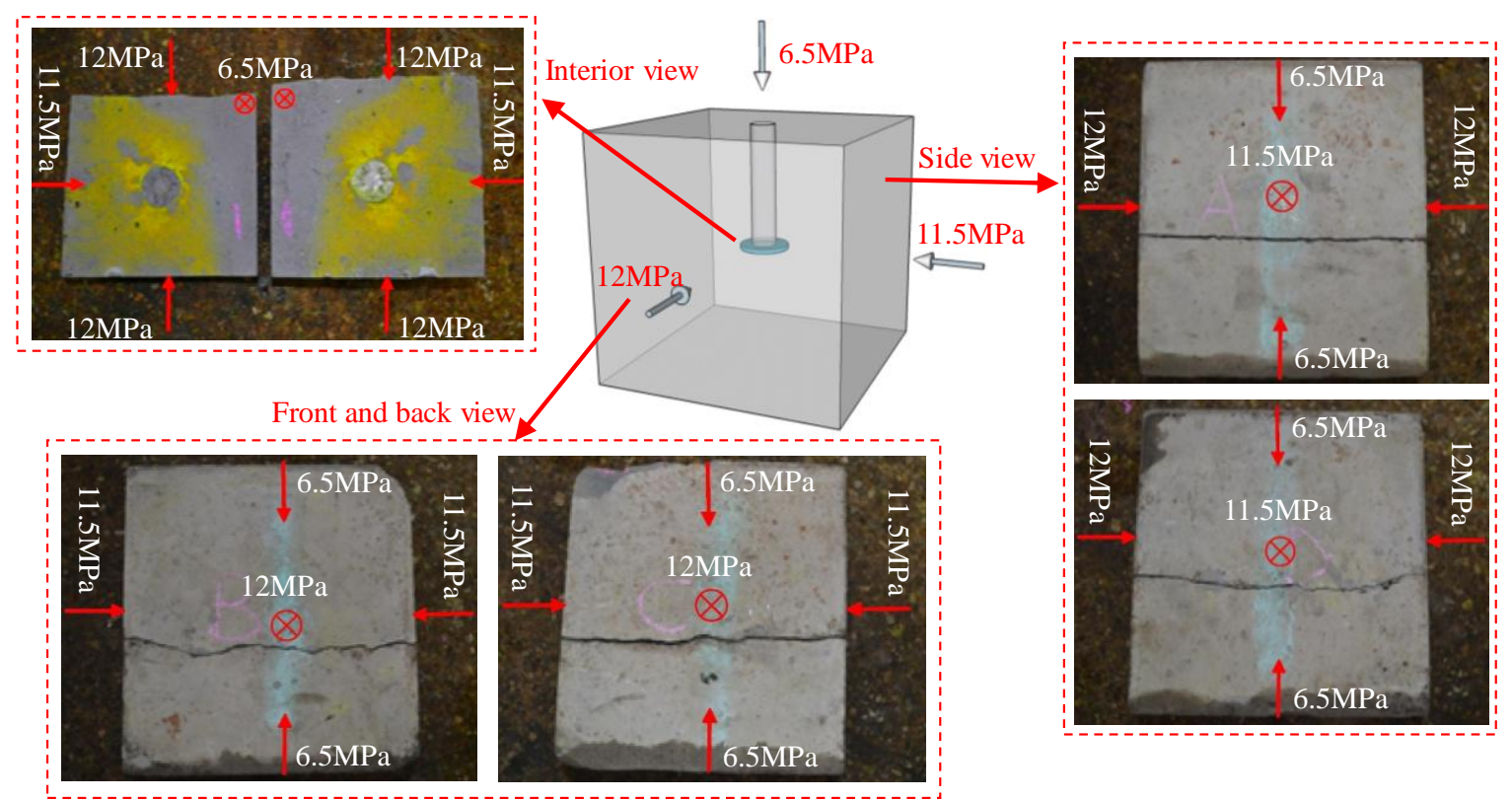

(a) Specimen 1 .
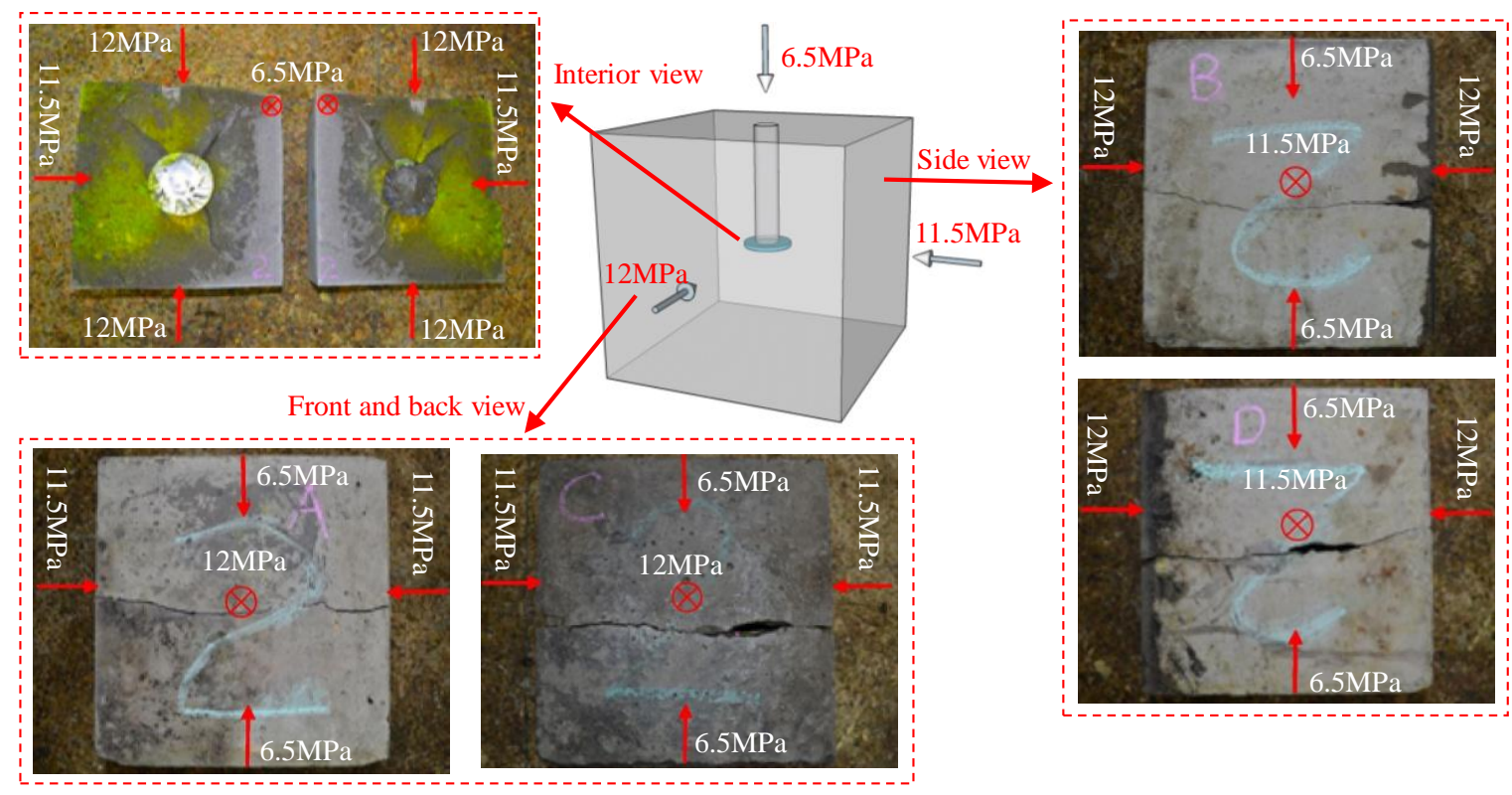

(b) Specimen 2 .

Figure 10. Cont. 


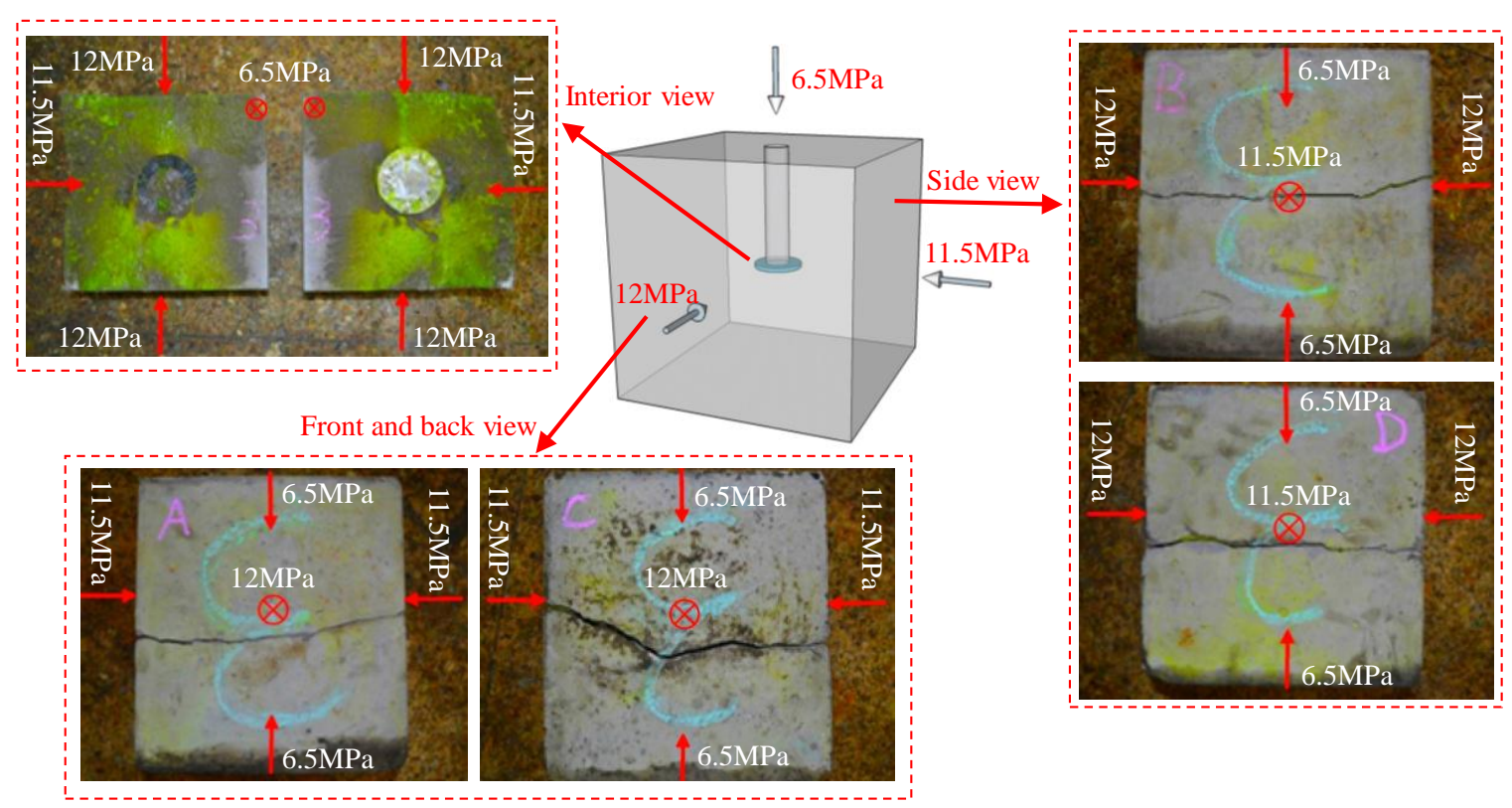

(c) Specimen 3.

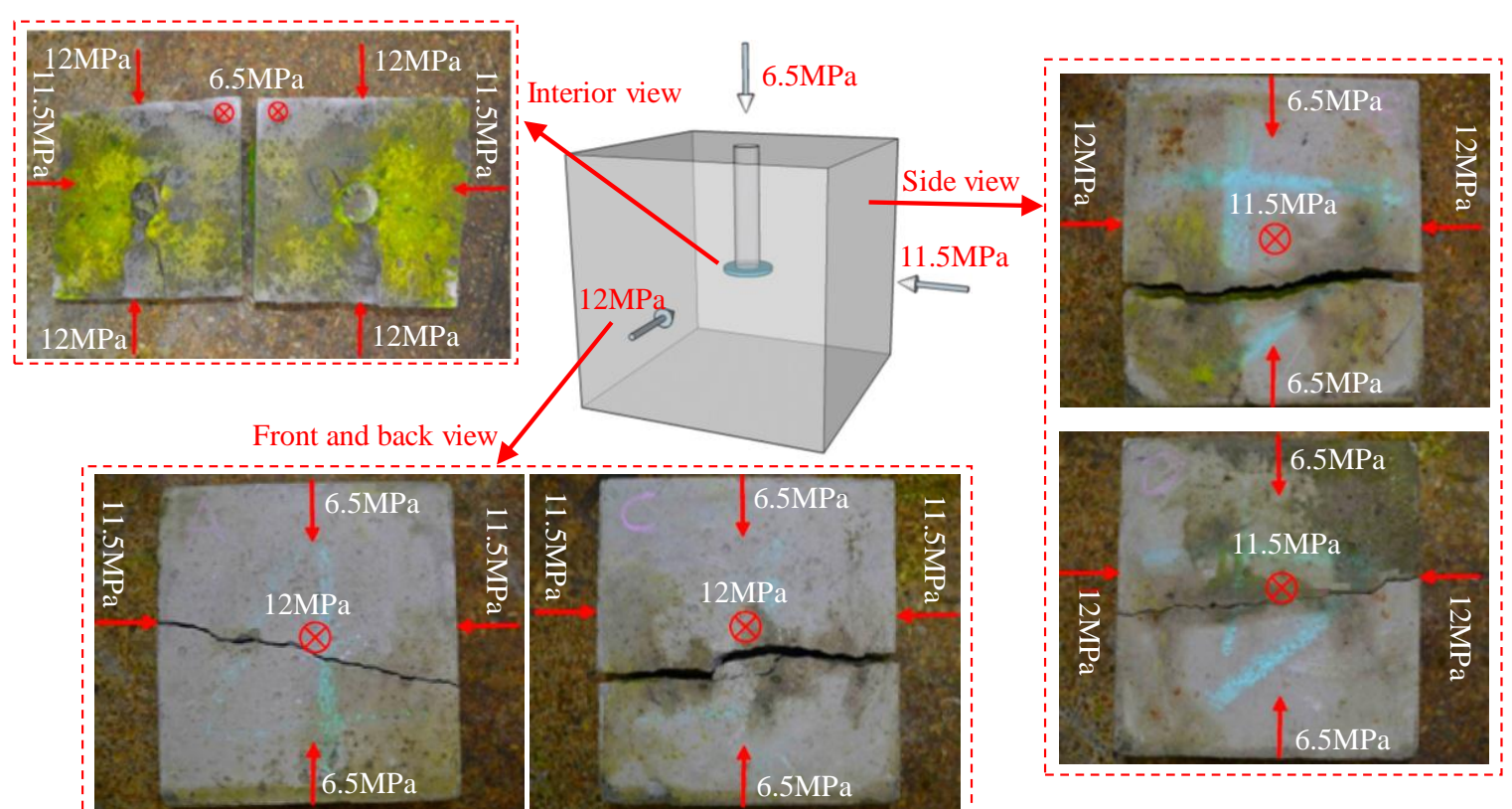

(d) Specimen 4.

Figure 10. Cont. 


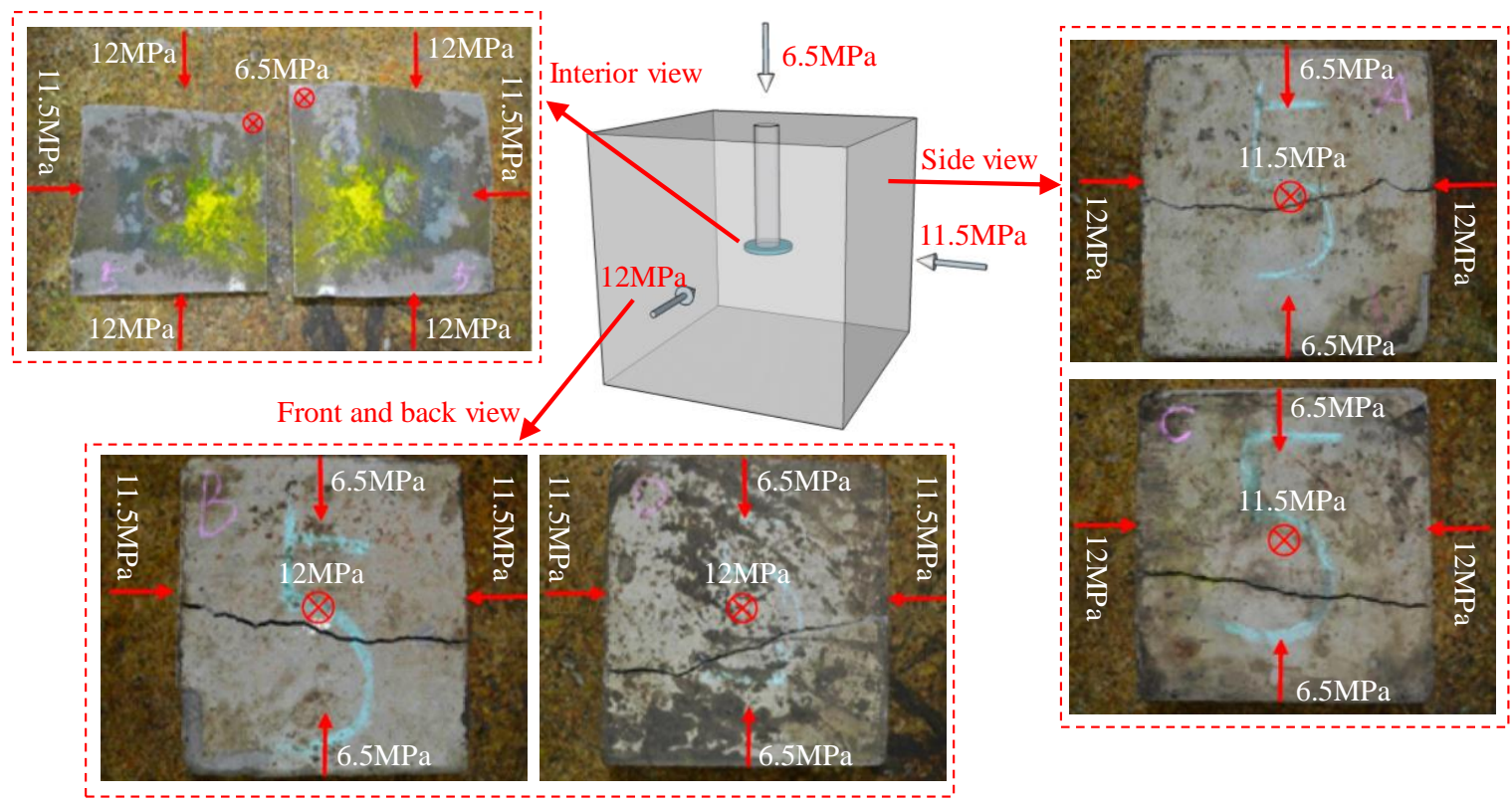

(e) Specimen 5 .

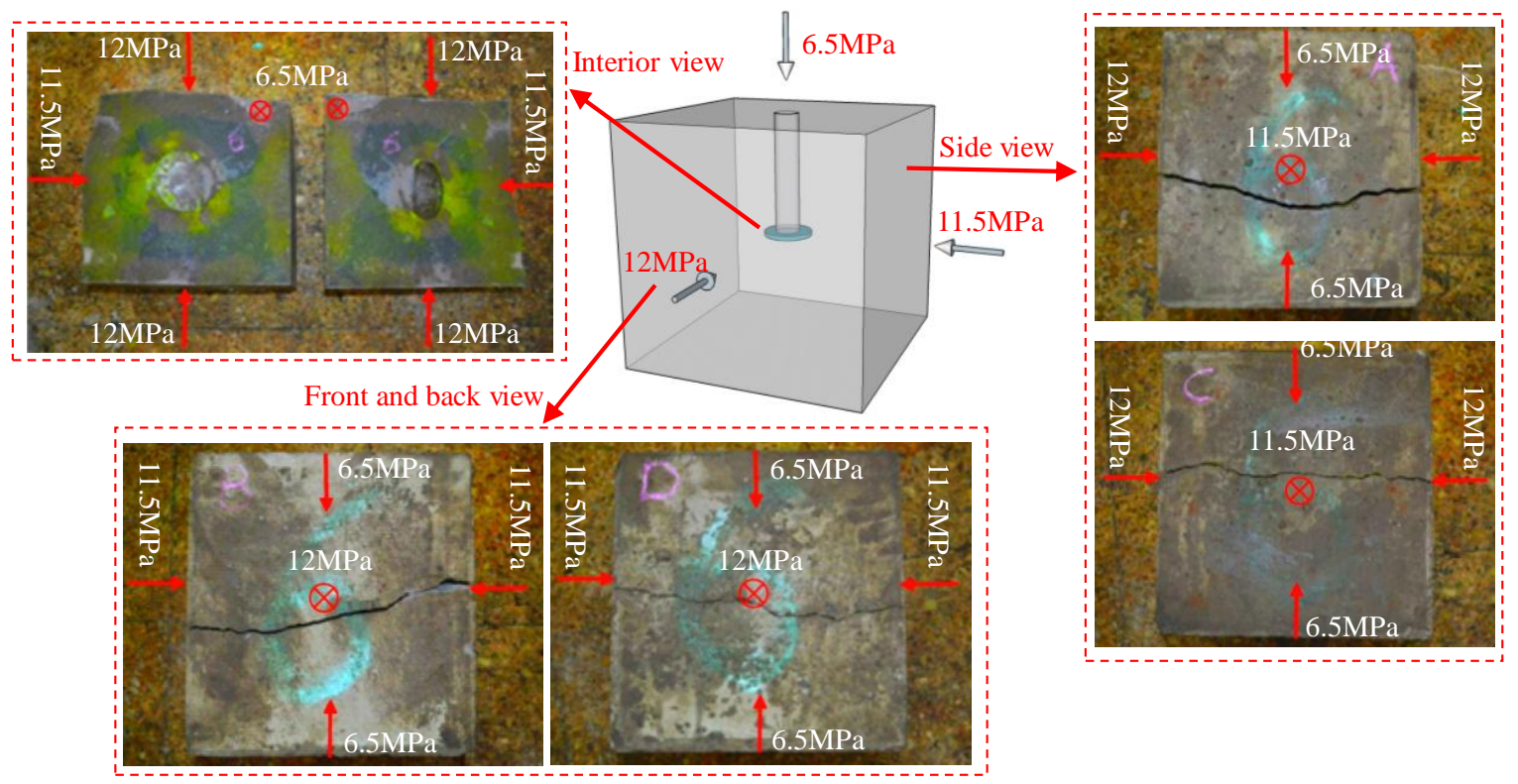

(f) Specimen 6 .

Figure 10. Hydraulic fracture configurations for the six specimens.

\section{Conclusions}

(1) A larger notch length and injection rate but a smaller notch angle is responsible for the decrease in fracture initiation pressure.

(2) The fracture propagation geometry may not be directly related to the notch length and injection rate but rather, governed by the notch angle.

(3) The propagation direction of a hydraulic fracture is at an angle to the horizontal direction and the surface of hydraulic fracture is a curved surface when the notch plane is not perpendicular to the direction of the minimum principal stress. 
Author Contributions: Y.C. designed and performed the tests and wrote the paper; Q.M. and J.Z. analyzed the data.

Funding: This work is supported by the China Postdoctoral Science Foundation under grant nos. 2017M620048 and 2018T110103.

Conflicts of Interest: The authors declare no conflict of interest.

\section{References}

1. Fallahzadeh, S.; Hossain, M.; Cornwell, A.J.; Rasouli, V. Near wellbore hydraulic fracture propagation from perforations in tight rocks: The roles of fracturing fluid viscosity and injection rate. Energies 2017, 10, 359. [CrossRef]

2. Figueiredo, B.; Tsang, C.F.; Rutqvist, J.; Niemi, A. The effects of nearby fractures on hydraulically induced fracture propagation and permeability changes. Eng. Geol. 2017, 228, 197-213. [CrossRef]

3. Lu, Y.Y.; Cheng, L.; Ge, Z.L.; Xia, B.W.; Li, Q.; Chen, J.F. Analysis on the initial cracking parameters of cross-measure hydraulic fracture in underground coal mines. Energies 2015, 8, 6977-6994. [CrossRef]

4. Lu, Y.Y.; Cheng, Y.G.; Ge, Z.L.; Cheng, L.; Zuo, S.J.; Zhong, J. Determination of fracture initiation locations during cross-measure drilling for hydraulic fracturing of coal seams. Energies 2016, 9, 358. [CrossRef]

5. Lu, Y.Y.; Zuo, S.J.; Ge, Z.L.; Xiao, S.Q.; Cheng, Y.G. Experimental study of crack initiation and extension induced by hydraulic fracturing in a tree-type borehole array. Energies 2016, 9, 514. [CrossRef]

6. Shimizu, H.; Ito, T.; Tamagawa, T.; Tezuka, K. A study of the effect of brittleness on hydraulic fracture complexity using a flow-coupled discrete element method. J. Pet. Sci. Eng. 2018, 160, 372-383. [CrossRef]

7. Wang, H. Numerical investigation of fracture spacing and sequencing effects on multiple hydraulic fracture interference and coalescence in brittle and ductile reservoir rocks. Eng. Fract. Mech. 2016, 157, 107-124. [CrossRef]

8. Fallahzadeh, S.; Rasouli, V.; Sarmadivaleh, M. An investigation of hydraulic fracturing initiation and near-wellbore propagation from perforated boreholes in tight formations. Rock Mech. Rock Eng. 2015, 48, 573-584. [CrossRef]

9. Wanniarachchi, W.A.M.; Gamage, R.P.; Perera, M.S.A.; Rathnaweera, T.D.; Gao, M.Z.; Padmanabhan, E. Investigation of depth and injection pressure effects on breakdown pressure and fracture permeability of shale reservoirs: An experimental study. Appl. Sci. 2017, 7, 664. [CrossRef]

10. Chen, Z.; Narayan, S.P.; Yang, Z.; Rahman, S.S. An experimental investigation of hydraulic behaviour of fractures and joints in granitic rock. Int. J. Rock Mech. Min. Sci. 2000, 37, 1061-1071. [CrossRef]

11. Zhou, J.; Chen, M.; Jin, Y.; Zhang, G.Q. Analysis of fracture propagation behavior and fracture geometry using a tri-axial fracturing system in naturally fractured reservoirs. Int. J. Rock Mech. Min. Sci. 2008, 45, 1143-1152. [CrossRef]

12. Zhou, J.; Jin, Y.; Chen, M. Experimental investigation of hydraulic fracturing in random naturally fractured blocks. Int. J. Rock Mech. Min. Sci. 2010, 47, 1193-1199. [CrossRef]

13. Liu, R.; Li, B.; Jiang, Y. Critical hydraulic gradient for nonlinear flow through rock fracture networks: The roles of aperture, surface roughness, and number of intersections. Adv. Water Resour. 2016, 88, 53-65. [CrossRef]

14. Liu, R.; Li, B.; Jiang, Y. A fractal model based on a new governing equation of fluid flow in fractures for characterizing hydraulic properties of rock fracture networks. Comput. Geotech. 2016, 75, 57-68. [CrossRef]

15. Liu, R.; Jiang, Y.; Li, B.; Wang, X. A fractal model for characterizing fluid flow in fractured rock masses based on randomly distributed rock fracture networks. Comput. Geotech. 2015, 65, 45-55. [CrossRef]

16. Liu, R.; Jiang, Y.; Li, B.; Yu, L. Estimating permeability of porous media based on modified Hagen-Poiseuille flow in tortuous capillaries with variable lengths. Microfluid. Nanofluid. 2016, 20, 120. [CrossRef]

17. Li, B.; Liu, R.; Jiang, Y. Influences of hydraulic gradient, surface roughness, intersecting angle, and scale effect on nonlinear flow behavior at single fracture intersections. J. Hydrol. 2016, 538, 440-453. [CrossRef]

(C) 2018 by the authors. Licensee MDPI, Basel, Switzerland. This article is an open access article distributed under the terms and conditions of the Creative Commons Attribution (CC BY) license (http:/ / creativecommons.org/licenses/by/4.0/). 